\title{
Theories and Frameworks for Online Education: Seeking an Integrated Model
}

\author{
Anthony G. Picciano \\ City University of New York Graduate Center and Hunter College
}

\begin{abstract}
This article examines theoretical frameworks and models that focus on the pedagogical aspects of online education. After a review of learning theory as applied to online education, a proposal for an integrated Multimodal Model for Online Education is provided based on pedagogical purpose. The model attempts to integrate the work of several other major theorists and model builders such as Anderson (2011).
\end{abstract}

Keywords: Online education, online learning, blended learning, learning theory, theoretical frameworks, model building, multimodal model

Picciano, A. G. (2017). Theories and frameworks for online education: Seeking an integrated model. Online Learning, 21(3), 166-190. doi: 10.24059/olj.v21i3.1225

\section{Introduction}

In a provocative chapter of The Theory and Practice of Online Learning, Terry Anderson (2011) examines whether a common theory for online education can be developed. While recognizing that as a difficult, and perhaps fruitless, task, he nonetheless examines possibilities and proposes his own theory which he admits is not complete. The purpose of this article is to examine theoretical frameworks relevant to the pedagogical aspects of online education. It starts with a consideration of learning theories and funnels down to their specific application to online education. The article concludes with a proposal for an integrated model for online education based on pedagogical purpose.

\section{Learning Theory}

Learning theory is meant to explain and help us understand how people learn; however, the literature is complex and extensive enough to fill entire sections of a library. It involves multiple disciplines, including psychology, sociology, neuroscience, and of course, education. Three of the more popular learning theories-behaviorism, cognitivism, and social constructivism - will be highlighted to form the foundation for further discussion. Mention will also be made of several other learning theories that are relevant to online education. Before reviewing these theories, it will be worthwhile to have a brief discussion of the term theory itself.

Theory is defined as a set of statements, principles, or ideas that relate to a particular subject. A theory usually describes, explains, and/or predicts phenomena. The definition of theory also varies depending upon disciplines, especially when related to the term model. As noted by Graham, Henrie, and Gibbons (2013), the two terms are used interchangeably and generally refer to the same concept. However, a model is more frequently a visual representation of reality or a concept. In this discussion, the terms theory and model will be used interchangeably. The purpose 
of a theory or model is to propose the answers to basic questions associated with a phenomenon. Graham, Henrie and Gibbons (2013) reviewed this issue as related to instructional technology and recommended a three-part taxonomy first proposed by Gibbons and Bunderson (2005) that includes theories that:

- Explore: "What exists?" and attempts to define [describe] and categorize;

- Explain: "Why does this happen?" and looks for causality and correlation, and work with variables and relationships.

- Design: "How do I achieve this outcome?" and describes interventions for reaching targeted outcomes and operational principles (Graham, Henrie and Gibbons, 2013, p. 13).

This taxonomy will serve as an overall guiding principle for the discussion of learning theories and models in this article.

\section{Behaviorism}

As its name implies, behaviorism focuses on how people behave. It evolved from a positivist worldview related to cause and effect. In simple terms, action produces reaction. In education, behaviorism examines how students behave while learning. More specifically, behaviorism focuses on observing how students respond to certain stimuli that, when repeated, can be evaluated, quantified, and eventually controlled for each individual. The emphasis in behaviorism is on that which is observable and not on the mind or cognitive processes. In sum, if you cannot observe it, it cannot be studied.

The development of behaviorism is frequently associated with Ivan Pavlov, famous for his experiments with dogs, food, and audible stimuli, such as a bell. In his experiments, dogs learned to associate food or feeding time with the sound of the bell and began to salivate. Pavlov conducted his experiments in the early 1900s and they were replicated by many other researchers throughout the $20^{\text {th }}$ century. John B. Watson, among the first Americans to follow Pavlov's work, saw it as a branch of natural science. Watson became a major proponent of Pavlov and is generally credited with coining the term behaviorism. He argued that mind and consciousness are unimportant in the learning process and that everything can be studied in terms of stimulus and response.

Other major figures associated with behaviorism are B.F. Skinner and Edward Thorndike. Skinner is particularly well known, primarily because he introduced what he referred to as operant conditioning which emphasized the use of both positive and negative reinforcement to help individuals learn new behaviors. This was quite different from Pavlov, who relied on simple reflexive responses to specific stimuli although both Pavlov and Skinner promoted repetitive behavior that leads to habit formation. Skinner had a significant influence on early computerassisted instructional (CAI) models as developed by Pat Suppes and others. A common aspect of early CAI programs was the reliance on encouragement and repetition to promote positive learning activities.

\section{Cognitivism}

Cognitivism has been considered a reaction to the "rigid" emphasis by behaviorists on predictive stimulus and response (Harasim, 2012, p. 58). Cognitive theorists promoted the concept that the mind has an important role in learning and sought to focus on what happens in between the occurrence of environmental stimulus and student response. They saw the cognitive processes of the mind, such as motivation and imagination, as critical elements of learning that bridge 
environmental stimuli and student responses. For example, Noam Chomsky (1959) wrote a critical review of Skinner's behaviorist work in which he raised the importance of creative mental processes that are not observable in the physical world. Although written mainly from the perspective of a linguist, Chomsky's view gained popularity in other fields, including psychology. Interdisciplinary in nature, cognitive science draws from psychology, biology, neuroscience, computer science, and philosophy to explain the workings of the brain as well as levels of cognitive development that form the foundation of learning and knowledge acquisition. As a result, cognitivism has evolved into one of the dominant learning theories. The future of cognitivism is particularly interesting as more advanced online software evolves into adaptive and personalized learning applications that seek to integrate artificial intelligence and learning analytics into instruction.

Behaviorism led to the development of taxonomies of learning because it emphasized the study and evaluation of multiple steps in the learning process. Behaviorists repeatedly studied learning activities to deconstruct and define the elements of learning. Benjamin Bloom (1956) was among the early psychologists to establish a taxonomy of learning that related to the development of intellectual skills and to stress the importance of problem solving as a higher order skill. Bloom's (1956) Taxonomy of educational objectives handbook: Cognitive domains remains a foundational text and essential reading within the educational community. Bloom's taxonomy is based on six key elements (see Figure 1) as follows:

- Creating: Putting elements together to form a coherent or functional whole, and reorganizing elements into a new pattern or structure through generating, planning, or producing.

- Evaluating: Making judgments based on criteria and standards through checking and critiquing.

- Analyzing: Breaking material into constituent parts, and determining how the parts relate to one another and to an overall structure or purpose through differentiating, organizing, and attributing.

- Applying: Carrying out or using a procedure through executing or implementing.

- Understanding: Constructing meaning from oral, written, and graphic messages through interpreting, exemplifying, classifying, summarizing, inferring, comparing, and explaining.

- Remembering: Retrieving, recognizing, and recalling relevant knowledge from long-term memory. 


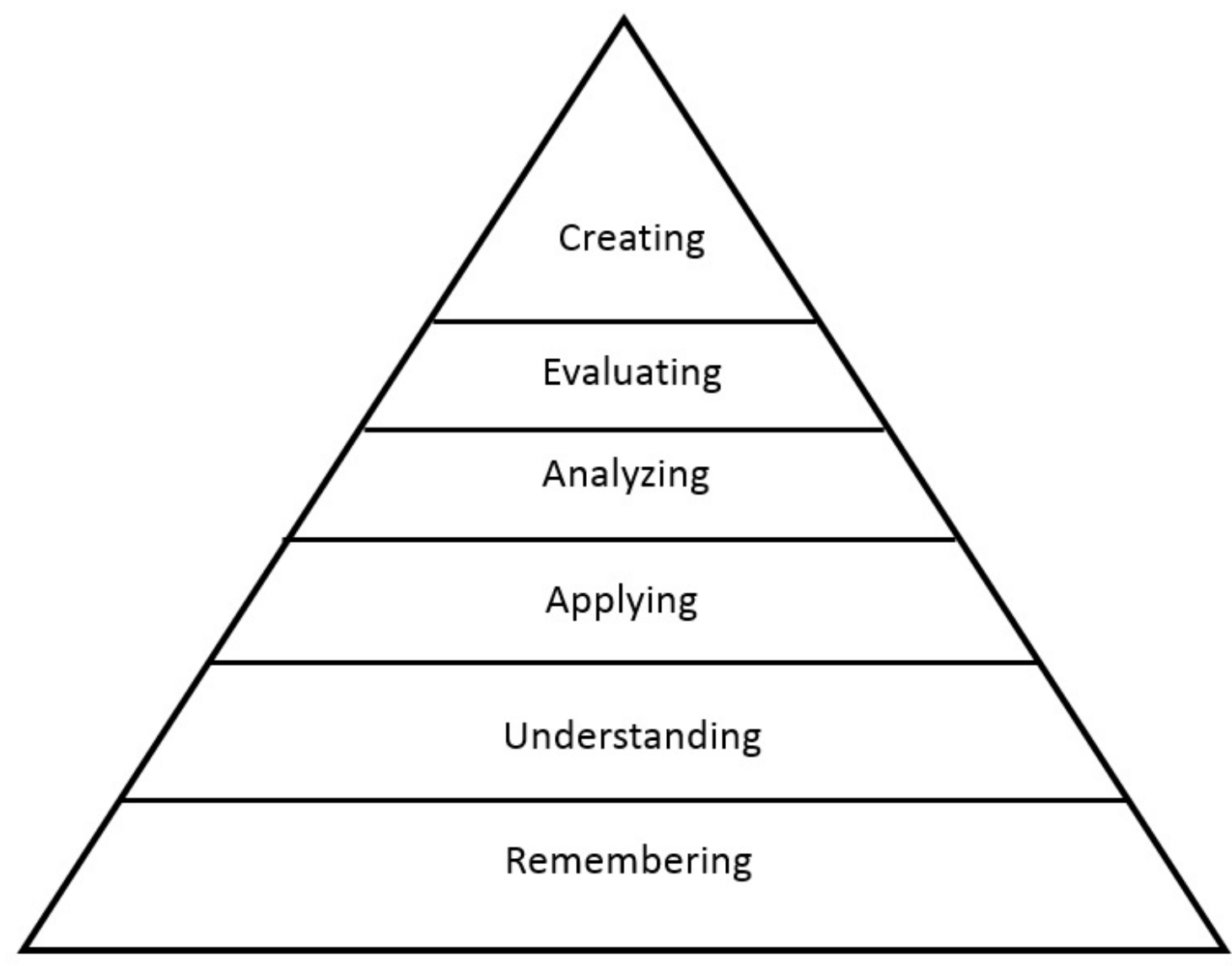

Figure 1. Bloom's Taxonomy

Bloom, in developing his taxonomy, essentially helped to move learning theory toward issues of cognition and developmental psychology. Twenty years later, Robert Gagne, an educational psychologist, developed another taxonomy (events of instruction) that built on Bloom's and became the basis for cognitivist instructional design (Harasim, 2012). Gagne emphasized nine events in instruction that drive the definitions of objectives and strategies for the design of instructional material. (See Figure 2) 
1. Gain attention: Use media relevant to the topic.

2. Describe the goal: Provide clear objectives to the overall course goals.

3. Stimulate prior knowledge: Review previously presented material and concepts and connect them to the material to be addressed in the current module.

4. Present the material to be learned: Readings, presentations, demonstrations, multimedia, graphics, audio files, animations, etc.

5. Provide guidance for learning: Discussions to enable learners to actively reflect on new information in order to check their knowledge and understanding of content.

6. Elicit performance: Activity-based learning such as group research projects, discussion, homework, etc.

7. Provide feedback: Immediate, specific, and constructive feedback is provided to students.

8. Assess performance: Assessment activity such as a test, research project, essay, or presentation.

9. Enhance retention and transfer: Provide opportunities for additional guided practice or projects that might relate learning to other real-life activities.

Figure 2. Gagne's Nine Events of Instruction

\section{Social Constructivism}

Parallel to behaviorism and cognitivism was the work of several education theorists, including Lev Vygotsky, John Dewey, and Jean Piaget. Their focus on social constructionism was to describe and explain teaching and learning as complex interactive social phenomena between teachers and students. Vygotsky posited that learning is problem solving and that the social construction of solutions to problems is the basis of the learning process. Vygotsky described the learning process as the establishment of a "zone of proximal development" in which the teacher, the learner, and a problem to be solved exist. The teacher provides a social environment in which the learner can assemble or construct with others the knowledge necessary to solve the problem. Likewise, John Dewey saw learning as a series of practical social experiences in which learners learn by doing, collaborating, and reflecting with others. While developed in the early part of the $20^{\text {th }}$ century, Dewey's work is very much in evidence in a good deal of present-day social constructivist instructional design. The use of reflective practice by both learner and teacher is a pedagogical cornerstone for interactive discussions that replaces straight lecturing, whether in a face-to-face or online class. Jean Piaget, whose background was in psychology and biology, based his learning theory on four stages of cognitive development that begin at birth and continue through one's teen years and beyond. Seymour Papert, in designing the Logo programming language, drew from Jean Piaget the concept of creating social, interactive microworlds or communities where children, under the guidance of a teacher, solve problems while examining social issues, mathematical and science equations, or case studies. Papert's approach of integrating computer technology into problem solving is easily applied to many facets of instructional design. 


\section{Derivatives of the Major Learning Theories}

A number of theories and models have roots in one or more of the above frameworks. In the latter part of the $20^{\text {th }}$ century, the major learning theories, especially cognitive theory and social constructivism, began to overlap. For example, Wenger and Lave (1991) and Wenger (1998) promoted concepts such as "communities of practice" and situated learning. Their position was that learning involves a deepening process situated in, and derived from, participation in a learning community of practice. Their work is very evident in many studies, including those related to online education.

Information processing learning theory is a variation of cognitivism that views the human mind as a system that processes information according to a set of logical rules. In it, the mind is frequently compared to a computer that follows a set of rules or program. Research using this perspective attempts to describe and explain changes in the mental processes and strategies that lead to greater cognitive competence as children develop. Richard Atkinson and Richard Shiffrin (1968) are generally credited with proposing the first information processing model that deals with how students acquire, encode, store (in short-term or long-term memory), and retrieve information.

One of the more popular and controversial theories relates to learning styles and posits that individuals learn differently depending upon their propensities and personalities. Carl Jung argued that individual personality types influence various elements of human behavior, including learning. Jung's theory focuses on four basic psychological dimensions:

1. Extroversion vs. Introversion

2. Sensation vs. Intuition

3. Thinking vs. Feeling

4. Judging vs. Perceiving

While each unique dimension can influence an individual learning style, it is likely that learning styles are based on a combination of these dimensions. For example, a learning style might include elements of extroversion, sensation, feeling, and perception as personality dimensions. Readers may be familiar with the Myers-Briggs Type Inventory (MBTI) which has been used for decades to assist in determining personality types, including how personality relates to student learning. The MBTI is based extensively on Jung's theories and has been used to predict and develop different teaching methods and environments and to predict individual patterns of mental functioning, such as information processing, idea development, and judgment formation. It can also be used to foretell patterns of attitudes and interests that influence an individual's preferred learning environment and to predict a person's disposition to pursue certain learning circumstances and avoid others. Lin, Cranton \& Bridglall (2005) remind us that much of the work of Carl Jung and the MBTI is applicable to learning environments, whether face-to-face or online. For example, the extrovert may prefer active, highly collaborative environments while the introvert would prefer less interaction and less collaboration. This suggests that instruction should be designed to allow both types of individuals - the outgoing social organizer as well as the introspective reflective observer- to thrive.

Howard Gardner has developed a theory of "multiple intelligences" that proposes that intelligence is not merely a singular entity but consists of multiple entities used by individuals in different proportions to understand and to learn about the world. Gardner has identified nine basic 
intelligences: linguistic, logical/mathematical, spatial, musical, bodily kinesthetic, interpersonal, intrapersonal, naturalistic, and existential (see Figure 3). Gardner's theory has received criticism from both psychologists and educators who view these "intelligences" as talents, personality traits, and abilities. His work has also been questioned by those who propose that there is, in fact, a root or base intelligence that drives the other "intelligences." Gardner does not necessarily disagree with this latter position but maintains that other intelligences can be viewed as main branches off the base root intelligence. This theory has important pedagogical implications and suggests the design of multiple learning modalities that allow learners to engage in ways they prefer, according to their interest or ability, and to challenge them to learn in other ways that are less related to their preferences, interests, or abilities. Gardner's work also addresses the common concern that too much teaching and learning is linguistically based (reading, writing, and speaking) and that the other intelligences are underutilized.

Modern neuroscience research also suggests that students learn in different ways depending upon a number of factors including age, learning stimuli, and the pace of instruction. Willingham (2008) suggests that learning is a dynamic process that may evolve and change from one classroom to another, from one subject to another, and from one day to another. This research also supports the concept that multiple intelligences and mental abilities do not exist as mere "yes/no" entities but within continua which the mind blends in a manner consistent with the way it responds and learns from the external environment and instructional stimuli. Conceptually, this suggests a framework for a multimodal instructional design that relies on a variety of pedagogical techniques, delivery approaches, and media.

Lastly, Malcom Knowles (1998) deserves mention as the individual who distinguished between andragogy (adult learning) and pedagogy (child learning). Adults, whether seeking to enhance their professional skills or to satisfy curiosity about a subject, learn differently than children. Courses designed for adults should tap into their social contexts and experiences. Knowles' insights are especially important for higher education, where online technology is used extensively for adult students in traditional and continuing education programs, competency-based learning, and career/professional development.

In sum, a number of theories have been, and will continue to be, applied to instruction, including online and blended learning. Several theories specifically related to online education will now be examined. 
1. Verbal-linguistic intelligence: well-developed verbal skills and sensitivity to the sounds, meanings, and rhythms of words

2. Logical-mathematical intelligence: ability to think conceptually and abstractly, and capacity to discern logical and numerical patterns

3. Spatial-visual intelligence: capacity to think in images and pictures, to visualize accurately and abstractly

4. Bodily-kinesthetic intelligence: ability to control one's body movements and to handle objects skillfully

5. Musical intelligences: ability to produce and appreciate rhythm, pitch, and timber

6. Interpersonal intelligence: capacity to detect and respond appropriately to the moods, motivations, and desires of others

7. Intrapersonal intelligence: capacity to be self-aware and in tune with inner feelings, values, beliefs, and thinking processes

8. Naturalist intelligence: ability to recognize and categorize plants, animals, and other objects in nature

9. Existential intelligence: sensitivity and capacity to tackle deep questions about human existence such as: What is the meaning of life? Why do we die? How did we get here?

Source: Gardner, H. (1983). Frames of Mind: The Theory of Multiple Intelligences. New York: Basic Books.

Figure 3. Gardner's Multiples Intelligences

\section{Learning Theories for Online Education}

Just as no single learning theory has emerged for instruction in general, the same is true for online education. A number of theories have evolved, most of which derive from the major learning theories discussed previously. In this section, several theories will be examined in terms of their appropriateness for the online environment.

\section{Community of Inquiry (CoI)}

The "community of inquiry" model for online learning environments developed by Garrison, Anderson \& Archer (2000) is based on the concept of three distinct "presences": cognitive, social, and teaching (see Figure 4). While recognizing the overlap and relationship among the three components, Anderson, Rourke, Garrison, and Archer (2001) advise further research on each component. Their model supports the design of online and blended courses as active learning environments or communities dependent on instructors and students sharing ideas, information, and opinions. Of particular note is that "presence" is a social phenomenon and manifests itself through interactions among students and instructors. The community of inquiry has become one of the more popular models for online and blended courses that are designed to be highly interactive among students and faculty using discussion boards, blogs, wikis, and videoconferencing. 


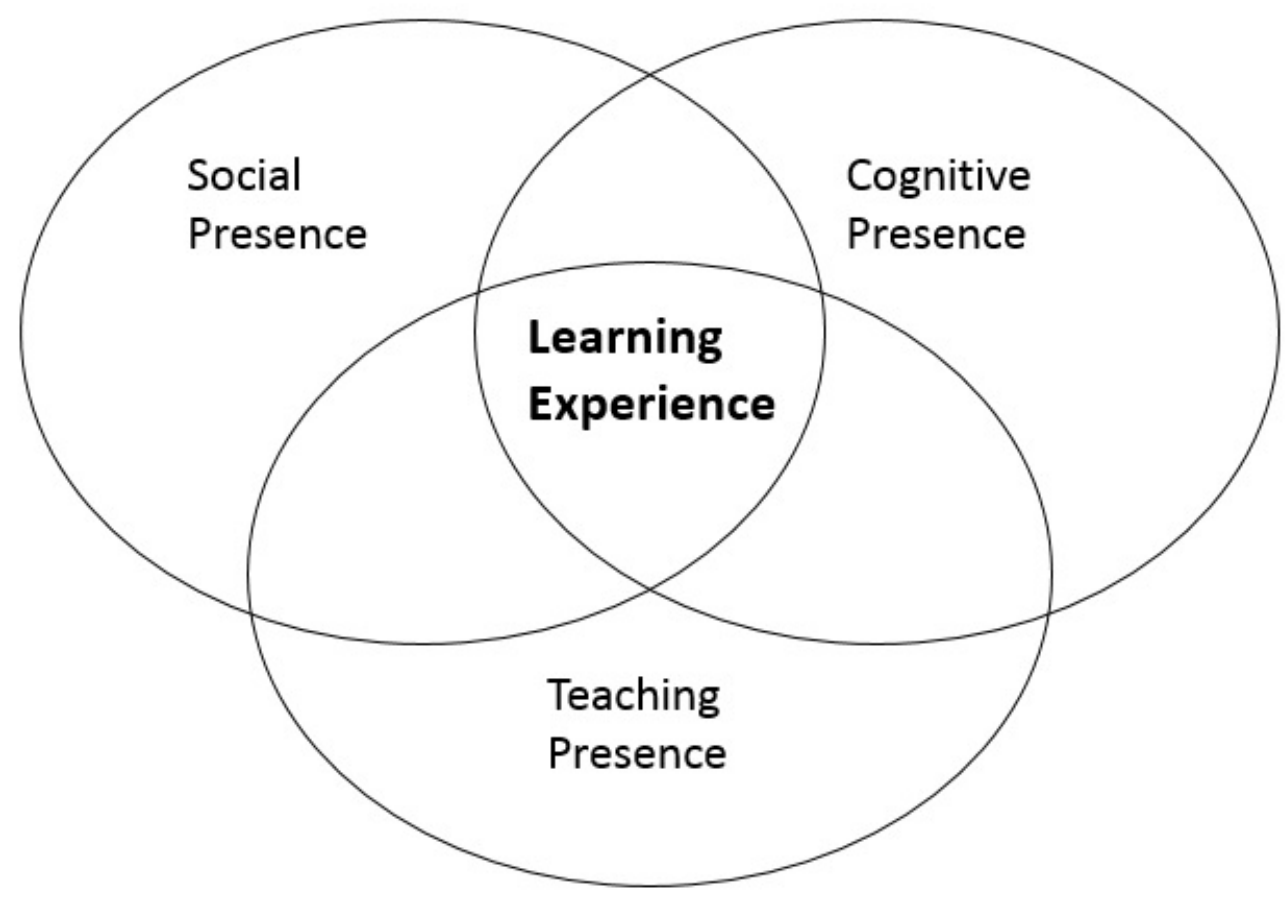

Figure 4. Community of Inquiry (Garrison, Anderson, Garrison and Archer, 2000)

\section{Connectivism}

George Siemens (2004), one of the early MOOC pioneers, has been the main proponent of connectivism, a learning model that acknowledges major shifts in the way knowledge and information flows, grows, and changes because of vast data communications networks. Internet technology has moved learning from internal, individualistic activities to group, community, and even crowd activities. In developing the theory, Siemens acknowledged the work of Alberto Barabasi and the power of networks. He also referenced an article written by Karen Stephensen (1998) entitled "What Knowledge Tears Apart, Networks Make Whole," which accurately identified how large-scale networks become indispensable in helping people and organizations manage data and information.

Siemens describes connectivism as:

the integration of principles explored by chaos, network, and complexity and selforganization theories [where] learning is a process that occurs within nebulous environments of shifting core elements - not entirely under the control of the individual. Learning (defined as actionable knowledge) can reside outside of ourselves (within an organization or a database), is focused on connecting specialized information sets, and the connections that enable us to learn more and are more important than our current state of knowing" (Siemens, 2004). 
Siemens noted that connectivism as a theory is driven by the dynamic of information flow. Students need to understand, and be provided with, experiences in navigating and recognizing oceans of constantly shifting and evolving information. Siemens proposed eight principles of connectivism (see Figure 5). Connectivism is particularly appropriate for courses with very high enrollments and where the learning goal or objective is to develop and create knowledge rather than to disseminate it.

1. Learning and knowledge rests in diversity of opinions.

2. Learning is a process of connecting specialized nodes or information sources.

3. Learning may reside in non-human appliances.

4. Capacity to know more is more critical than what is currently known.

5. Nurturing and maintaining connections is needed to facilitate continual learning.

6. Ability to see connections between fields, ideas, and concepts is a core skill.

7. Currency (accurate, up-to-date knowledge) is the intent of all connectivist learning activities.

8. Decision making is itself a learning process. Choosing what to learn and the meaning of incoming information is seen through the lens of a shifting reality. While there is a right answer now, it may be wrong tomorrow due to alterations in the information climate affecting the decision.

Figure 5. Siemens' Eight Principles of Connectivism

\section{Online Collaborative Learning (OCL)}

Online collaborative learning (OCL) is a theory proposed by Linda Harasim that focuses on the facilities of the Internet to provide learning environments that foster collaboration and knowledge building. Harasim describes OCL as:

a new theory of learning that focuses on collaborative learning, knowledge building, and Internet use as a means to reshape formal, non-formal, and informal education for the Knowledge Age" (Harasim, 2012, p. 81).

Like Siemens, Harasim sees the benefits of moving teaching and learning to the Internet and largescale networked education. In some respects, Harasim utilizes Alberto Barabasi's position on the power of networks. In OCL, there exist three phases of knowledge construction through discourse in a group:

1. Idea generating: the brainstorming phase, where divergent thoughts are gathered

2. Idea organizing: the phase where ideas are compared, analyzed, and categorized through discussion and argument 
3. Intellectual convergence: the phase where intellectual synthesis and consensus occurs, including agreeing to disagree, usually through an assignment, essay, or other joint piece of work (Harasim, 2012, p. 82).

OCL also derives from social constructivism, since students are encouraged to collaboratively solve problems through discourse and where the teacher plays the role of facilitator as well as learning community member. This is a major aspect of OCL but also of other constructivist theories where the teacher is not necessarily separate and apart but rather, an active facilitator of, knowledge building. Because of the importance of the role of the teacher, OCL is not easy to scale up. Unlike connectivism, which is suited for large-scale instruction, OCL is best situated in smaller instructional environments. This last issue becomes increasingly important when seeking commonality among online education theories.

Many other theories can be associated with online education but, rather than present more theories and in keeping with one of the major purposes of this article, it is appropriate to ask whether an integrated or unified theory of online education is possible.

\section{Can We Build a Common Integrated Theory of Online Education?}

As noted, Terry Anderson (2011) examined the possibility of building a theory of online education, starting with the assumption that it would be a difficult, and perhaps impossible, task. He approached this undertaking from a distance education perspective, having spent much of his career at Athabasca University, the major higher education distance education provider in Canada. While he acknowledged that many theorists and practitioners consider online learning as "a subset of learning in general" (Anderson, 2011, p. 46-47), he also stated:

online learning as a subset of distance education has always been concerned with provision of access to educational experience that is, at least more flexible in time and in space as campus-based education (Anderson, 2011, p. 53).

These two perspectives (subset of learning in general and subset of distance education) complicate any attempt to build a common theory of online education. Blended learning models, for instance, do not easily fit into the distance education schema, even though they are evolving as a prevalent component of traditional face-to-face and online education environments.

Anderson considered a number of theories and models but focused on the well-respected work of Bransford, Brown, and Cocking (1999) who posited that effective learning environments are framed within the convergence of four overlapping lenses: community-centeredness, knowledge-centeredness, learner-centeredness, and assessment centeredness. These lenses provided the foundational framework for Anderson's approach to building an online education theory, as he examined in detail the characteristics and facilities that the Internet provides with regards to each of the four lenses. Second, he noted that the Internet had evolved from a text-based environment to one in which all forms of media are supported and readily available. He also accurately commented that the Internet's hyperlink capacity is most compatible with the way human knowledge is stored and accessed. In this regard, he referred to the work of Jonassen (1992) and Shank (1993) who associated hyperlinking with constructivism. Finally, Anderson extensively examined the importance of interaction in all forms of learning and referred to a number of mostly distance education theorists such as Holmberg (1989), Moore (1989), Moore and Kearsley (1996), and Garrison and Shale (1990). The essence of interaction among students, teachers, and content is well understood and is referenced in many theories of education, especially constructivism. 
Anderson's evaluation of interaction concludes that interactions are critical components of a theory.

With these three elements in mind (the Bransford, Brown, and Cocking lenses, the affordances and facilities of the Internet, and interaction), Anderson then proceeded to construct a model (see Figure 6). He did add one important element by distinguishing community/collaborative models from self-paced instructional models, commenting that community/collaborative models and self-paced instructional models are inherently incompatible. The community/collaborative models do not scale up easily because of the extensive interactions among teachers and students. On the other hand, the self-paced instructional models are designed for independent learning with much less interaction among students and teachers.

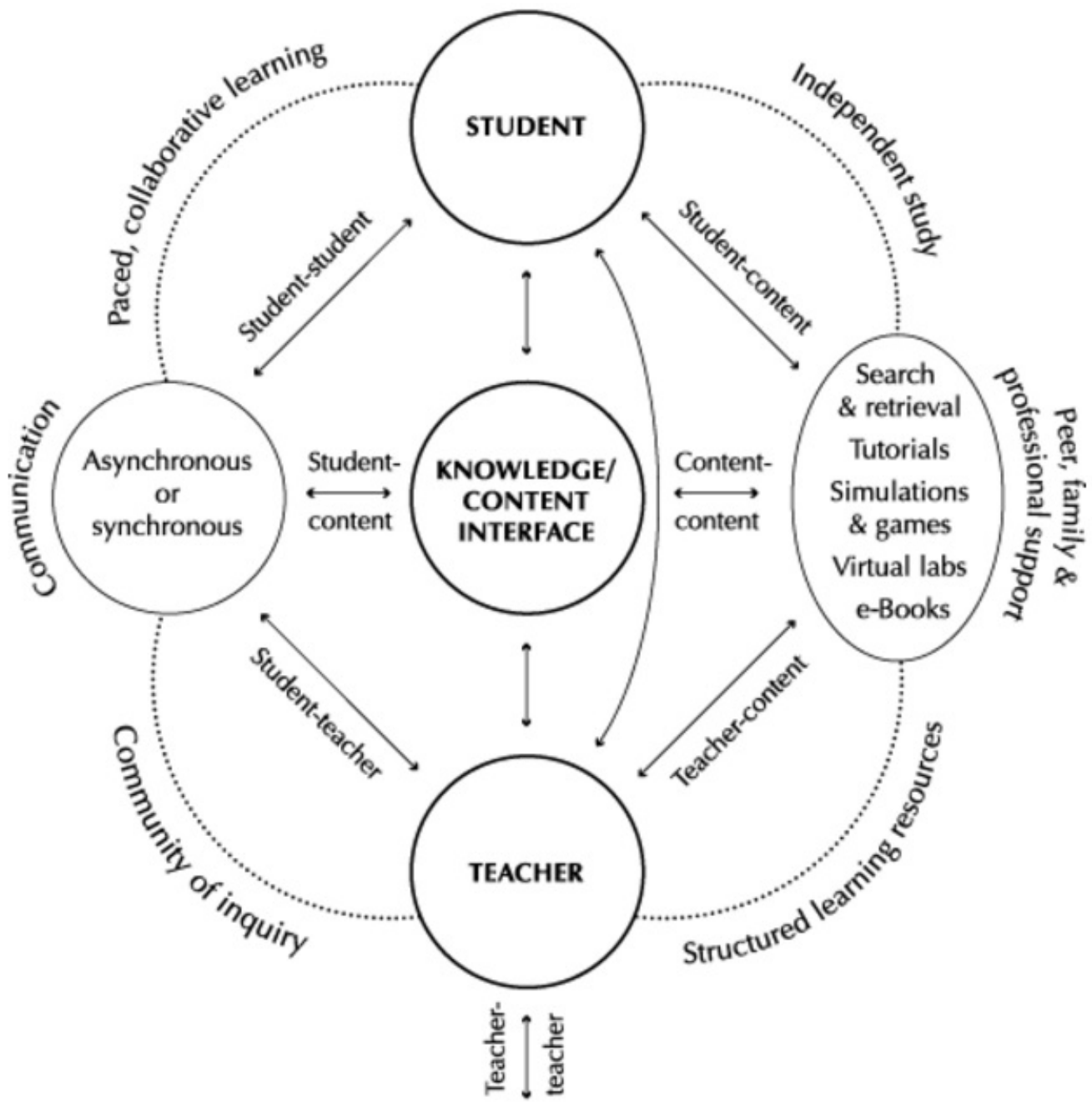

OTHER TEACHERS

Figure 6. Anderson's Online Learning Model. Reprinted with permission by Anderson, T. (2011). The theory and practice of online learning. ( $2^{\text {nd }}$ Edition). Edmonton, AB: AU Press. 
Figure 6 illustrates:

the two major human actors, learners and teachers, and their interactions with each other and with content. Learners can of course interact directly with content that they find in multiple formats, and especially on the Web; however, many choose to have their learning sequenced, directed, and evaluated with the assistance of a teacher. This interaction can take place within a community of inquiry, using a variety of Net-based synchronous and asynchronous activities... These environments are particularly rich, and allow for the learning of social skills, the collaborative learning of content, and the development of personal relationships among participants. However, the community binds learners in time, forcing regular sessions or at least group-paced learning. The second model of learning (on the right) illustrates the structured learning tools associated with independent learning. Common tools used in this mode include computer-assisted tutorials, drills, and simulations (Anderson, 2011, p. 61-62).

Figure 6 demonstrates the instructional flow within the two sides and represents the beginnings of a theory or model from the distance education perspective. Anderson concluded that his model "will help us to deepen our understanding of this complex educational context" (Anderson, 2011, p. 68), which he noted needs to measure more fully the direction and magnitude of each input variable on relevant outcome variables.

Anderson also commented about the potential of the Internet for education delivery, and that an online learning-based theory or model could subsume all other modes with the exception of the "rich face-to-face interaction in formal classrooms" (Anderson, 2011, p. 67). This becomes a quandary for Anderson in trying to develop a common theory of online education in that it does not provide for in-person, face-to-face activity and is problematic for those who see online education as a subset of education in general.

\section{An Integrated Model}

Anderson's model assumed that none of the instruction is delivered in traditional, face-toface mode, and so excluded blended learning models that have some face-to-face component. Is it possible, therefore, to approach the search for an integrated model for online education from the face-to-face education in general or even the blended learning perspective?

Bosch (2016), in a review of instructional technology, identified and compared four blended learning models using twenty-one different design components. These models emphasized, to one degree or another, the integration of pedagogy and technology in course design. Among the models was a Blending with Pedagogical Purpose Model (see Figure 7), developed by this author, in which pedagogical objectives and activities drive the approaches, including the online technology that faculty members use in instruction. The model also suggests that blending the objectives, activities, and approaches within multiple modalities might be most effective for, and appeal to, a wide range of students. The model contains six basic pedagogical goals, and approaches for achieving them, to form learning modules. The model is flexible and assumes that other modules can be added as needed and where appropriate. The most important feature of this model is that pedagogy drives the approaches that will work best to support student learning. The modules are also shown as intersecting but this is optional; they may or may not intersect or overlap depending upon the approaches used. For instance, some reflection can be incorporated into collaboration or not, depending upon how the collaborative activity is designed. It might be 
beneficial to have the collaborative groups reflect specifically on their activities. Similar scenarios are possible for the other modules. Ultimately important is that all the modules used blend together into a coherent whole. The following paragraphs briefly review each of these modules.

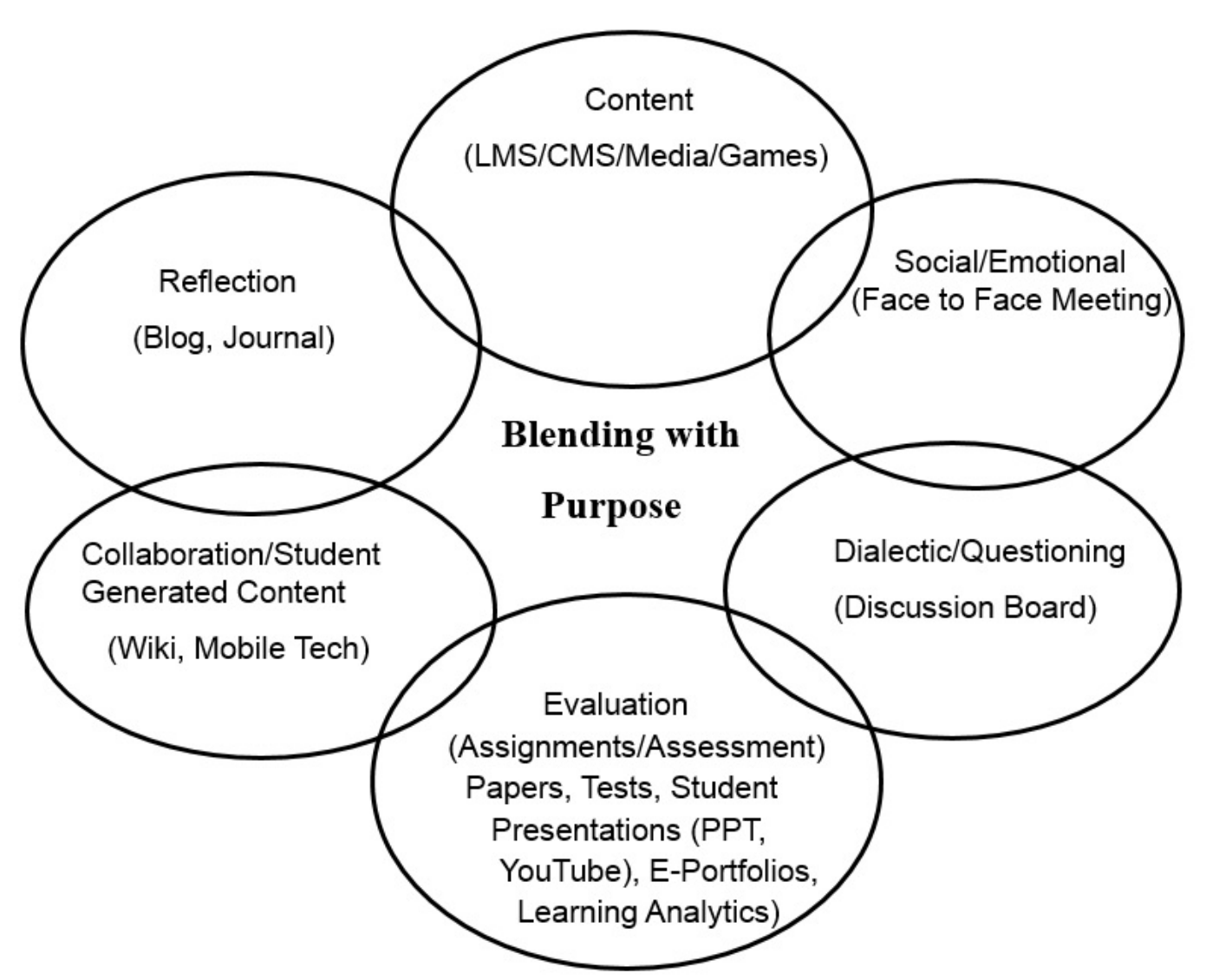

Figure 7. Blending with Pedagogical Purpose Model

Content is one of the primary drivers of instruction and there are many ways in which content can be delivered and presented. While much of what is taught is delivered linguistically (teacher speaks/students listen or teacher writes/students write), this does not have to be the case, either in face-to-face or online environments. Mayer (2009) has done extensive reviews of the research and has concluded that learning is greatly enhanced by visualization. Certain subject areas, such as science, are highly dependent upon the use of visual simulations to demonstrate processes and systems. The humanities, especially art, history, and literature, can be greatly enhanced by rich digital images as well. Course/learning management systems (CMS/LMS) such as Blackboard, Canvas, or Moodle provide basic content delivery mechanisms for blended learning and easily handle the delivery of a variety of media including text, video, and audio. Games have also evolved and now play a larger role in instructional content. In providing and presenting content, the Blending with Pedagogical Purpose model suggests that multiple technologies and media be utilized. 
The Blending with Pedagogical Purpose model posits that instruction is not simply about learning content or a skill but also supports students socially and emotionally. As noted, constructivists view teaching and learning as inherently social activities. The physical presence of a teacher or tutor, in addition to providing instruction, is comforting and familiar. While perhaps more traditionally recognized as critical for K-12 students, social and emotional development must be acknowledged as important to education at all levels. Faculty members who have taught graduate courses know that students, even at this advanced level, frequently need someone with whom to speak, whether to help understand a complex concept or to provide advice about career and professional opportunities. While fully online courses and programs have evolved to the point where faculty members can provide some social and emotional support where possible and appropriate, in blended courses and programs this is more frequently provided in a face-to-face mode.

Dialectics or questioning is an important activity that allows faculty members to probe what students know and to help refine their knowledge. The Socratic Method remains one of the major techniques used in instruction, and many successful teachers are proud of their ability to stimulate discussion by asking the "right" questions to help students think critically about a topic or issue. In many cases, these questions serve to refine and narrow a discussion to very specific "points" or aspects of the topic at hand, and are not meant to be open-ended activities. For dialectic and questioning activities, a simple-to-use, threaded electronic discussion board or forum such as VoiceThread is an effective approach. A well-organized discussion board activity generally seeks to present a topic or issue and have students respond to questions and provide their own perspectives, while evaluating and responding to the opinions of others. The simple, direct visual of the "thread" also allows students to see how the entire discussion or lesson has evolved. In sum, for instructors who want to focus attention and dialogue on a specific topic, the main activity for many online courses has been, and continues to be, the electronic discussion board.

Reflection can be incorporated as a powerful pedagogical strategy under the right circumstances. There is an extensive body of scholarship on the "reflective teacher" and the "reflective learner" dating from the early $20^{\text {th }}$ century (Dewey (1916), Schon (1983)). While reflection can be a deeply personal activity, the ability to share one's reflections with others can be beneficial. Pedagogical activities that require students to reflect on what they learn and to share their reflections with their teachers and fellow students extend and enrich reflection. Blogs and blogging, whether as group exercises or for individual journaling activities, have evolved into appropriate tools for student reflection and other aspects of course activities.

Collaborative learning has evolved over decades. In face-to-face classes, group work grew in popularity and became commonplace in many course activities. Many professional programs, such as business administration, education, health science, and social work, rely heavily on collaborative learning as a technique for group problem solving. In the past, the logistics and time needed for effective collaboration in face-to-face classes were sometimes problematic. Now, email, mobile technology, and other forms of electronic communication alleviate some of these logistical issues. Wikis, especially, have grown in popularity and are becoming a staple in group projects and writing assignments. They are seen as important vehicles for creating knowledge and content, as well as for generating peer-review and evaluation (Fredericksen, 2015). Unlike faceto-face group work that typically ended up on the instructor's desk when delivered in paper form, wikis allow students to generate content that can be shared with others during and beyond the end 
of a semester. Papers and projects developed through wikis can pass seamlessly from one group to another and from one class to another.

Evaluation of learning is perhaps the most important component of the model. CMSs/LMSs and other online tools and platforms provide a number of mechanisms to assist in this area. Papers, tests, assignments, and portfolios are among the major methods used for student learning assessment, and are easily done electronically. Essays and term projects pass back and forth between teacher and student without the need for paper. Oral classroom presentations are giving way to YouTube videos and podcasts. The portfolio is evolving into an electronic multimedia presentation of images, video, and audio that goes far beyond the three-inch, paperfilled binder. Weekly class discussions on discussion boards or blogs provide the instructor with an electronic record that can be reviewed over and over again to examine how students have participated and progressed over time. They are also most helpful to instructors to assess their own teaching and to review what worked and what did not work in a class. Increasingly, learning analytics are seen as the mechanisms for mining this trove of data to improve learning and teaching. In sum, online technology allows for a more seamless sharing of evaluation and assessment activities, and provides a permanent, accessible record for students and teachers.

The six components of the model described above form an integrated community of learning in which rich interaction, whether online or face-to-face, can be provided and blended across all modules. Furthermore, not every course must incorporate all of the activities and approaches of the model. The pedagogical objectives of a course should drive the activities and, hence, the approaches. For example, not every course needs to require collaborative learning or dialectic questioning. In addition to individual courses, faculty and instructional designers might consider examining an entire academic program to determine which components of the model best fit with overall programmatic goals and objectives. Here, the concept of learning extends beyond the course to the larger academic program where activities might integrate across courses. For example, some MBA programs enroll a cohort of students into three courses in the same semester but require that one or more assignments or projects be common to all three courses.

The critical question for our discussion, however, is whether this Blending with Pedagogical Purpose model can be modified or enlarged to be considered a model for online education in general. By incorporating several of the components from other theories and models discussed earlier in this article, this is a possibility. Figure 8 presents a Multimodal Model for Online Education that expands on the Blending with Purpose approach and adds several new components from Anderson and others, namely, community, interaction, and self-paced, independent instruction. 


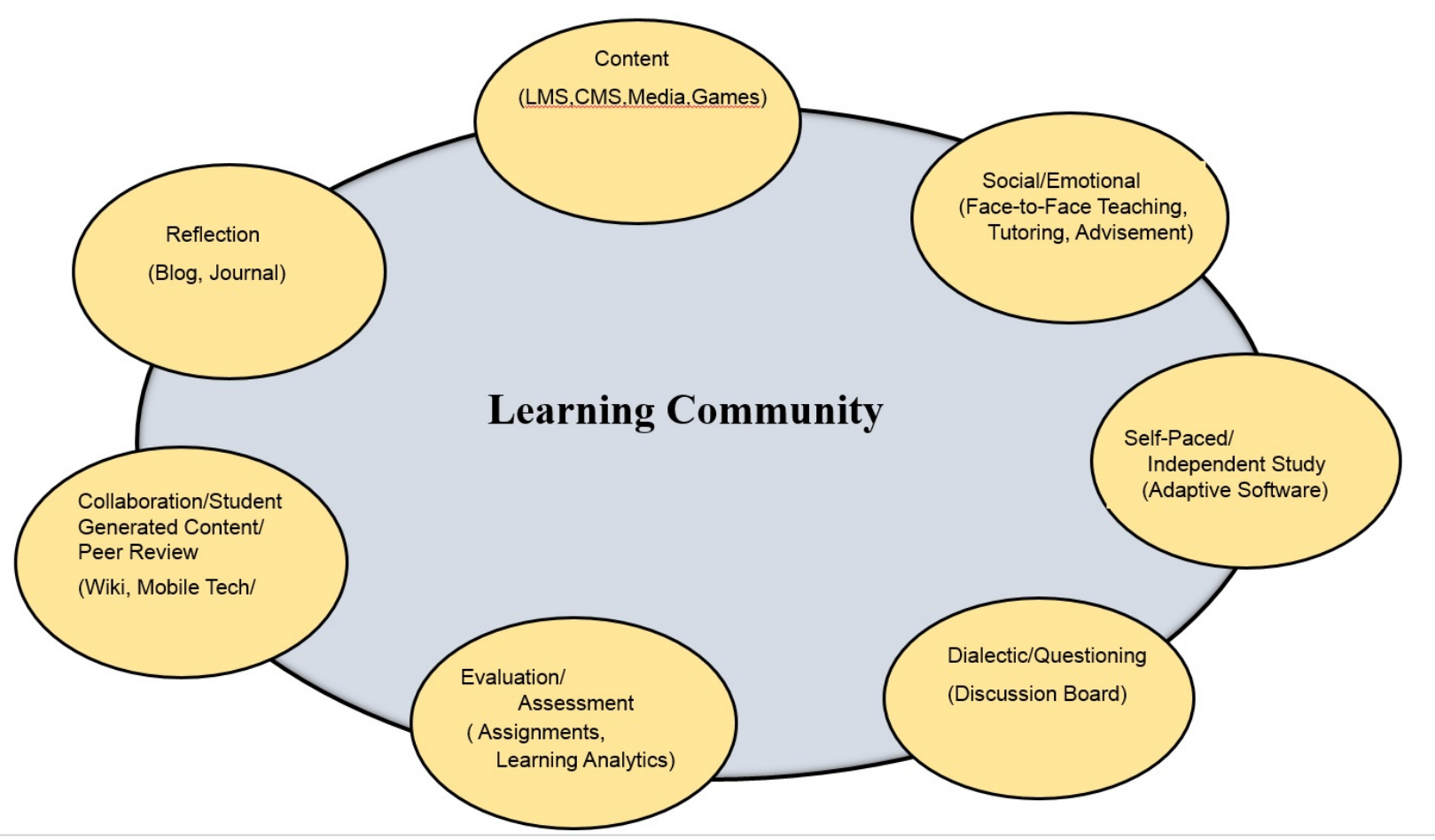

Figure 8. Multimodal Model for Online Education

First, the concept of a learning community as promoted by Garrison, Anderson \& Archer (2000) and Wenger and Lave (1991) is emphasized. A course is conceived of as a learning community. This community can be extended to a larger academic program. Second, it is understood that interaction is a basic characteristic of the community and permeates the model to the extent needed. Third, and perhaps the most important revision, is the addition of the selfstudy/independent learning module that Anderson emphasized as incompatible with any of the community-based models. In this model, self-study/independent learning can be integrated with other modules as needed or as the primary mode of instructional delivery. Adaptive learning software, an increasingly popular form of self-study, can stand alone or be integrated into other components of the model. The latter is commonly done at the secondary school level where adaptive software programs are used primarily in stand-alone mode with teachers available to act as tutors when needed. Adaptive software is also integrated into traditional, face-to-face classes, such as science, where it is possible to have the instructor assign a lab activity that uses adaptive learning simulation software.

This Multimodal Model of Online Education attempts to address the issues that others, particularly Terry Anderson, have raised regarding elements that might be needed for an integrated or unified theory or model for online education. Whether or not this model finds acceptance is not yet clear. It is hoped that this article might serve as a vehicle for a critical examination of the model. 


\section{Applying the Integrated Model}

To provide a clearer understanding of the integrated model, several examples of its application follow. Figure 9A provides an example of the model as a representation of a self-paced, fully online course. The three major components [in green] for this course are: content as provided on an CMS/LMS, a self-paced study module, and assessment/evaluation. Other components of the model, such as a blog or discussion board to allow interaction among students, could be included but are not necessarily needed. This example is most appropriate for online programs that have rolling admissions and students are not limited by a semester schedule. Students proceed at their own pace to complete the course as is typical in some distance education programs. This example is scalable and can be used for large numbers of students.
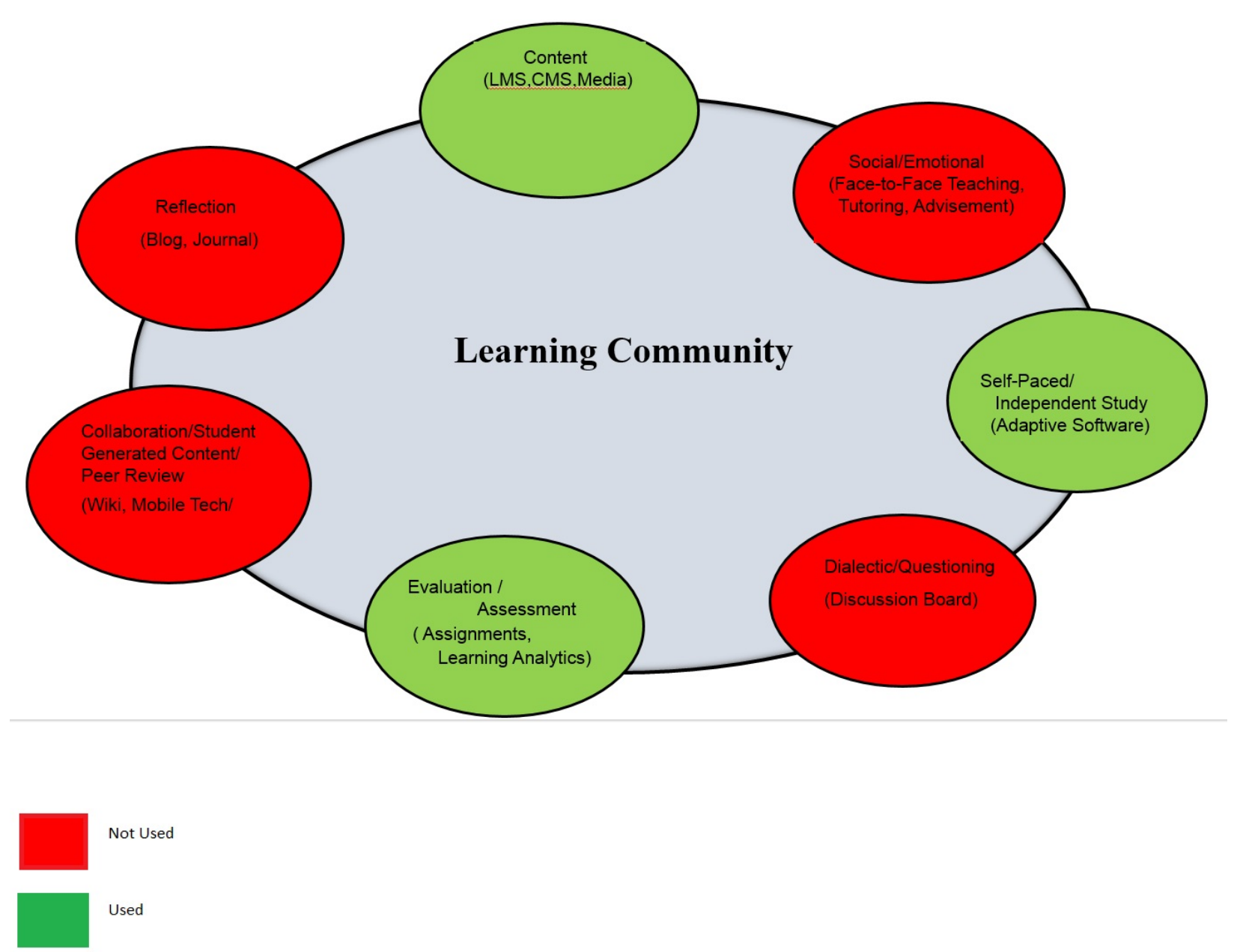

Not Used

Used

Figure 9A. Example of a Distance Education Course 
Figure 9B provides an example of another course that is primarily a self-paced, online course similar to that described in Figure 9A but is designed to have a teacher or tutor available as needed. A discussion board is also included to allow for ongoing interaction among students and teacher. This course would follow a semester schedule and would have a standard class size although most of the instruction would be provided by the self-paced study module. A standard course organization would be used, with a teacher or tutor assigned to guide and assist with instruction. The teacher or tutor could help students struggling with any of the self-paced material. This type of course is increasingly common in secondary schools, such as in credit-recovery courses.

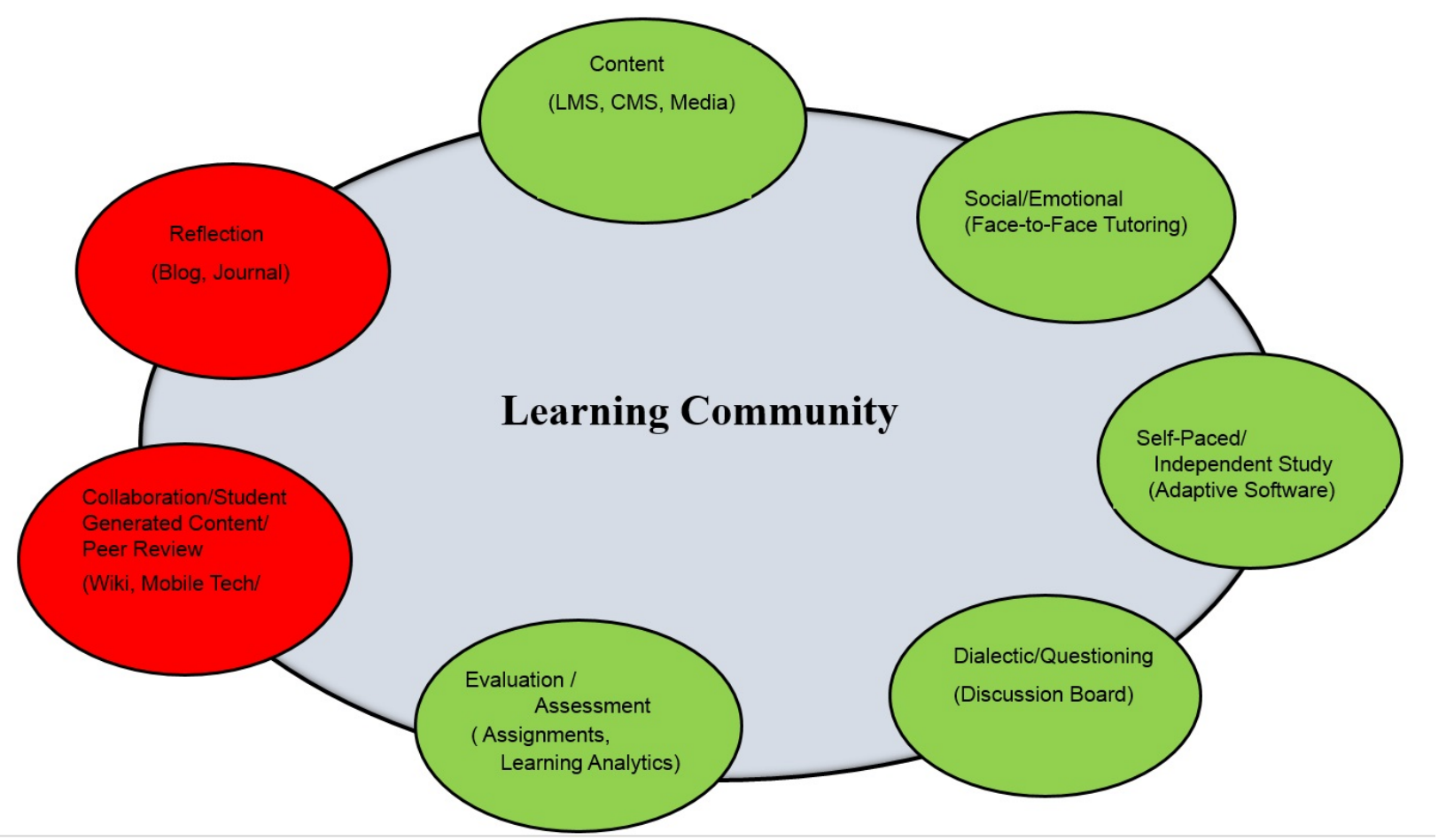

Figure 9B. Example of a Modified Distance Education Course

Figure 9C provides an example of a teacher-led, fully online course. Presentation of the course content is provided by a LMS or CMS along with other media and is used as needed by the teacher. The discussion board, blog, and wiki provide facilities for interaction among teachers and students, students and students, and students and content. In this course, the teacher could direct students to watch a fifteen-minute lecture available in the LMS database and then ask students to 
respond to a series of questions on the discussion board. Student responses can then be used as the basis for an interactive discussion board activity among students, guided by the teacher. The model also provides for reflection and collaborative activities.

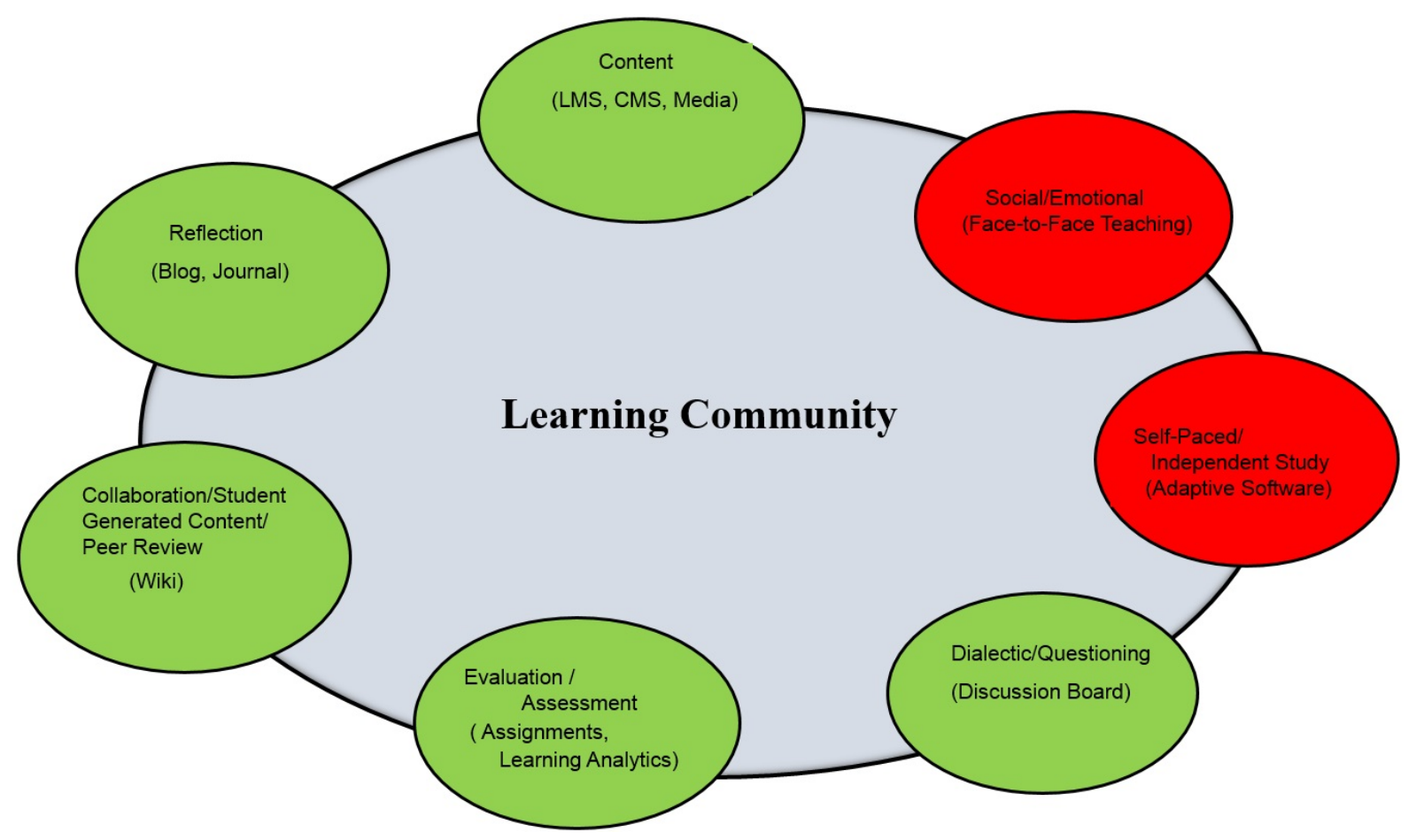

Figure 9C. Example of a Teacher-Led Fully Online Course

Figure 9D provides an example of a blended course with instruction provided primarily by a teacher. The other modules are used to extend and enrich instruction. The teacher is the major guide for instruction and would be supplemented by content as needed by a CMS/LMS. The course would meet in a face-to-face classroom although some instructional activity would also be conducted online, either on a discussion board, a blog, or a collaborative wiki. The teacher would establish beforehand portions of the course that would meet in the face-to-face and online modes. 


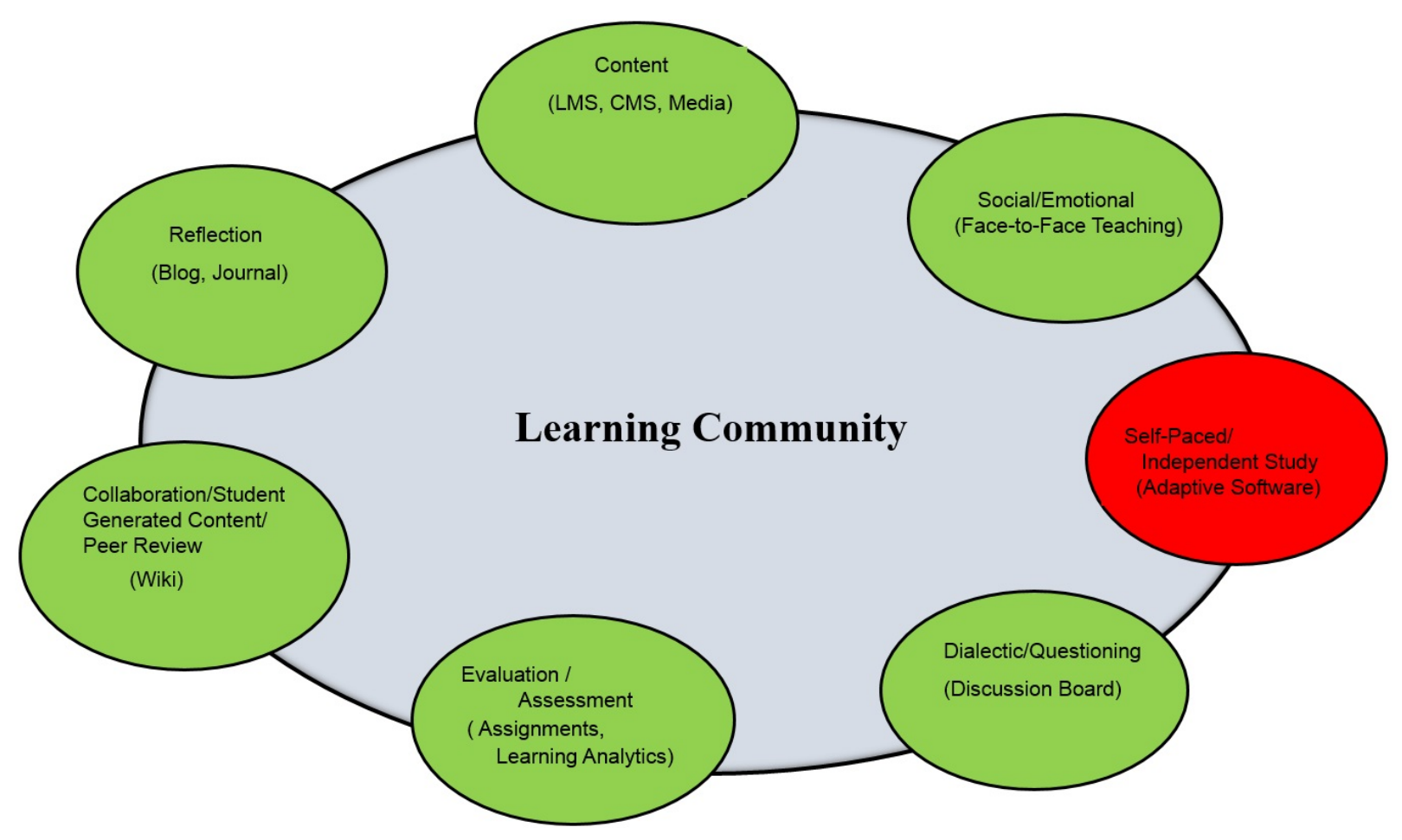

Not Used

Used

Figure 9D. Example of a Mainstream Blended Course

\section{Attributes and Limitations of the Multimodal Model}

The proposed Multimodal Model for Online Education includes many of the major attributes of other learning and online education theories and models. For example, behaviorists will find elements of self-study and independent learning in adaptive software. Cognitivists might appreciate reflection and dialectic questioning as important elements of the model. Social constructivists will welcome the emphasis on community and interaction throughout the model. Connectivists might value the collaboration and the possibility of student-generated content. Perhaps the most significant element of the model is its flexibility and ability to expand as new learning approaches, perhaps spurred by advances in technology, evolve.

The model is not without limitations. Learning theories can be approached through a number of perspectives and disciplines. Behavioral psychologists, cognitive psychologists, sociologists, and teacher educators might emphasize the need for deeper considerations of their perspectives for an online learning theory. The multimodal model here represents an integrated composite of several such perspectives but is essentially a pedagogical model and, therefore, may have greater appeal to instructional designers, faculty, and others who focus on learning objectives. 


\section{Conclusion}

In this article, a number of major theories related to technology were presented, beginning with a review of major theories associated with learning. One critical question concerned whether an integrated or unified theory of online education could be developed. The work of Terry Anderson was highlighted. The article proposed an integrated model that described the phenomenon of pedagogically driven online education. Key to this model is the assumption that online education has evolved as a subset of learning in general rather than a subset of distance learning. As blended learning, which combines face-to-face and online instruction, evolves into the dominant form of instruction throughout all levels of education, it serves as the basis for an integrated model. It is likely that, in the not-too-distant future, all courses and programs will have some online learning components, as suggested in this integrated model.

Note: This article is adapted from a chapter in a forthcoming book by the author, tentatively entitled Online Education: Theory and Practice, available in 2018 from Routledge/Taylor \& Francis, Publishers. 


\section{References}

Anderson, T. (2011). The theory and practice of online learning ( $2^{\text {nd }}$ Edition). Edmonton, AB: AU Press.

Anderson, T., Rourke, L., Garrison, D.R, and Archer, W. (2001). Assessing social presence in asynchronous text-based computer conferencing. Journal of Asynchronous Learning Networks, 5(2) Retrieved from: http://immagic.com/eLibrary/ARCHIVES/GENERAL/ATHAB CA/Anderson.pdf

Atkinson, R. C., \& Shiffrin, R. M. (1968). Human memory: A proposed system and its control processes. In Spence, K. W., \& Spence, J. T. The psychology of learning and motivation (Volume 2). New York: Academic Press. pp. 89-195.

Barabasi, A. L. (2002). Linked: The new science of networks. Cambridge, MA: Perseus Publishing.

Bloom, B. S. (1956). Taxonomy of educational objectives handbook: Cognitive domains. New York: David McKay.

Bosch, C. (2016). Promoting Self-Directed Learning through the Implementation of Cooperative Learning in a Higher Education Blended Learning Environment. Johannesburg, SA: Doctoral dissertation at North-West University.

Bransford, J., Brown, A., \& Cocking, R. (1999). How people learn: Brain, mind experience and school. Washington, D.C.: National Academy Press/National Research Council. Retrieved from: http://www.colorado.edu/MCDB/LearningBiology/readings/Howpeople-learn.pdf

Chomsky, N. (1959). A review of B. F. Skinner's Verbal Behavior. Language, 35(1), 26-58.

Dewey, J. (1916). Democracy and education. New York: The Free Press.

Fredericksen, E. (February 4, 2015). Is online education good or bad? And is this really the right question? The Conversation. Retrieved from: https://theconversation.com/is-onlineeducation-good-or-bad-and-is-this-really-the-right-question-35949

Gagné, R. M. (1977). The conditions of learning. New York: Holt, Rinehart \& Winston.

Gardner, H. (1983). Frames of mind: The theory of multiple intelligences. New York: Basic Books.

Garrison, D. R., Anderson, T., \& Archer, W. (2000). Critical inquiry in a text-based environment: Computer conferencing in higher education model. The Internet and Higher Education, 2(2-3), 87-105. 
Garrison, D.R. \& Shale, D. (1990). Education at a distance: From issues to practice. Malabar: FL: Robert E. Krieger.

Gibbons, A. S., \& Bunderson, C. V. (2005). Explore, explain, design. In K. K. Leondard (Ed.), Encyclopedia of Social Measurement (pp. 927-938). New York, NY: Elsevier.

Graham, C. R., Henrie, C. R., \& Gibbons, A. S. (2013). Developing models and theory for blended learning research. In A. G. Picciano, C. D. Dziuban, \& C. R. Graham (Eds.), Blended learning: Research perspectives, volume 2. New York, NY: Routledge.

Harasim, L. (2012). Learning theory and online technologies. New York: Routledge/Taylor \& Francis.

Holmberg, B. (1989). Theory and practice of distance education. London: Routledge.

Jonassen, D. (1992). Designing hypertext for learning. In E. Scanlon \& T. O'Shea (Eds.), New directions in educational technology (pp. 123-130). Berlin: Springer-Verlag.

Jung,C. Psychological types. Original in German. Zurich: Rascher Verlag. (1921). There are a number of English translations.

Knowles, M.S., Holton, E.F. \& Swanson, R.A. The adult learner (5 ${ }^{\text {th }}$ Edition). Houston: Butterworth-Heinemann Publishers, 1998.

Lin, L., Cranton, P., \& Bridglall, B. (2005). Psychological type and asynchronous written dialogue in adult learning. Teachers College Record Volume 107 (8), 1788-1813.

Mayer, R. E. (2009). Multimedia learning (2 ${ }^{\text {nd }}$ edition). New York: Cambridge University Press.

Moore, M. (1989). Three types of interaction. American Journal of Distance Education, 3(2), $1-6$.

Moore, M. \& Kearsley, G. (1996). Distance education: A systems view. New York: Wadsworth Publishing Company.

McLuhan, Marshall (1964). Understanding media. London: Routledge.

Picciano, A.G. (2009). Blending with purpose: The multimodal model. Journal of Asynchronous Learning Networks, 13 (1). Needham, MA: The Sloan Consortium. pp. 7-18.

Schon, D. (1983). Reflective practitioner: How professionals think in action. New York: Basic Books. 
Shank, G. (1993). Abductive multiloguing: The semiotic dynamics of navigating the Net. The Arachnet Electronic Journal of Virtual Culture, 1(1). Retrieved from: http://serials.infomotions.com/aejvc/aejvc-v1n01-shank-abductive.txt

Siemens, G. (2004). Connectivism: A learning theory for the digital age. Paper retrieved from: http://www.elearnspace.org/Articles/connectivism.htm

Stephenson, K., (1998). Internal Communication, No. 36: What Knowledge Tears Apart, Networks Make Whole. Retrieved from http:/www.netform.com/html/icf.pdf

Wenger, E. \& Lave, J. (1991). Situated learning: Legitimate peripheral participation (Learning in doing: Social, cognitive and computational Perspectives. Cambridge: Cambridge University Press.

Wenger, E. (1998). Communities of practice: Learning, meaning, and identity. Cambridge: Cambridge University Press.

Willingham, D. (Summer, 2008). What is developmentally appropriate? American Educator, 32(2), pp. 34-39. 